\title{
Momentum flux associated with gravity waves in the low-latitude troposphere
}

\author{
S. R. Prabhakaran Nayar and S. Sreeletha \\ Department of Physics, University of Kerala, Kariavattom, Trivandrum-695 581 India \\ Received: 29 November 2001 - Revised: 7 November 2002 - Accepted: 14 November 2002
}

\begin{abstract}
The vertical fluxes of horizontal momentum at tropospheric heights are calculated for four days, 25-28 August 1999. The mean zonal wind during these days show the presence of strong westward wind at the upper troposphere. Both the symmetric beam radar method and the power spectral method of evaluation of vertical flux of zonal and meridional momentum shows nearly the same result for quiet conditions. The temporal evolution of the momentum flux is estimated for a day with strong zonal shear and convection. These results indicate that on 28 August 1999, the strong downward vertical wind in the lower altitude range is associated with upward vertical flux of zonal momentum, and strong upward vertical wind is associated with downward vertical flux. Similarly, the strong shear in zonal wind is associated with the increase in negative values in vertical flux in the upper troposphere. Analysis of the role of wave periods in the transport of momentum flux indicates that the vertical momentum flux magnitude is not evenly distributed in all wave periods, but instead it peaks at certain wave periods in the range 10 to $100 \mathrm{~min}$.
\end{abstract}

Key words. Meteorology and atmospheric dynamics (convective process; tropical meteorology; precipitation)

\section{Introduction}

Internal gravity waves generated in the lower atmosphere through various processes, such as convection and wind shear, play a vital role in the transfer of mean horizontal momentum from the ground level or from one layer of the atmosphere to another layer. Early estimates of energy and momentum fluxes due to gravity waves suggested that their effects at upper heights might be significant (Gossard, 1962; Hines, 1965, 1972; Lindzen, 1968; Bretherton, 1969). Subsequent studies related the wave parameters to the momentum and thermal budgets of the mesosphere (Houghton,

Correspondence to: S. R. Prabhakaran Nayar

(srp@md2.vsnl.net.in)
1978; Lindzen, 1981). Vincent and Reid (1983) presented a technique in which ground-based radar can be used to measure fluxes directly, and the technique has been applied to mesospheric (Vincent and Fritts, 1987; Tsuda et al., 1990), tropospheric and lower stratospheric heights (Fukao et al., 1988; McAfee et al., 1989; Fritts et al., 1990; Thomas et al., 1992). Fritts and Vincent (1987) found that about $70 \%$ of the momentum flux is due to gravity waves with periods less than one hour. Sato (1989) and Fritts et al. (1990) investigated the momentum flux as a function of frequency by expanding the technique of Vincent and Reid (1983).

Fritts and Vanzandt (1993) provided a general formulation of the mean energy spectrum, as well as estimated wave energy and momentum fluxes in the lower and middle atmosphere. Nakamura et al. (1993) observed day-to-day variations in the gravity wave activity. They found that variations in zonal momentum flux seem to show good correlation with shear and mean zonal wind each day and thereby suggested that day-to-day variations of gravity waves are caused by variations of wind shear. Vertical flux of horizontal momentum in the troposphere and lower stratosphere have been studied by Prichard and Thomas (1993) and Worthington and Thomas (1996) using MST radar at Aberystwyth. They found that momentum fluxes for long period waves show little changes with activity, whereas momentum flux values of shorter periods are enhanced substantially during active periods. Chang et al. (1997) have estimated the vertical fluxes of zonal and meridional momentum and found them to be in the range $\pm 0.02 \mathrm{~kg} \mathrm{~m}^{-1} \mathrm{~s}^{-2}$ and $\pm 0.01 \mathrm{~kg} \mathrm{~m}^{-1} \mathrm{~s}^{-2}$, respectively. Gravity wave generation and propagation in the tropical easterly jet region was studied by calculating momentum fluxes and $\mathrm{KH}$ instability at different tropospheric and lower stratospheric heights using Indian MST radar by Sasi et al. (1998). Gravity waves generated by jet induced wind shears are observed using Indian MST radar (Rao et al., 2000).

The purpose of the present study is to estimate vertical flux of horizontal momentum at tropospheric heights by symmetric beam technique (Vincent and Reid, 1983) and to study the 
frequency response using the power spectral method (Sato, 1989), using the Indian MST radar at a low-latitude station at different conditions of the atmosphere. We have also studied both the frequency dependence of momentum flux for the short period gravity waves in the periodic range 10-100 min. The study of temporal evolution of vertical momentum flux and its association with wind shear and convection on $28 \mathrm{Au}-$ gust 1999 is also presented and discussed.

\section{Radar experiment and data acquisition}

The Indian MST radar operates at $53 \mathrm{MHz}$, located at Gadanki $\left(13.47^{\circ} \mathrm{N}, 79.18^{\circ} \mathrm{E}\right)$, is a highly sensitive atmospheric radar. The radar has a phased antenna array consisting of 1024 crossed three element Yagi antenna extending over an area of $130 \times 130 \mathrm{~m}^{2}$. The average power aperture product of the radar is $7 \times 10^{8} \mathrm{~W} \mathrm{~m}^{2}$, and it generates a radiation pattern with a $3^{\circ}$ half-power beam width gain of $36 \mathrm{~dB}$ and a side lobe level of $-20 \mathrm{~dB}$. The two oblique beams are with a $10^{\circ}$ off zenith direction. Details of the MST radar system are given by Rao et al. (1995). To investigate the short period gravity waves, in the periodic range $10-100 \mathrm{~min}$, the MST radar was operated continuously for about seven hours on each day during 25-28 August 1999 in the 5 beam (east, west, zenith $\mathrm{X}$, north and south) mode. The radar was operated with $16 \mu$ s-coded pulse and 1-ms inter-pulse period, providing an altitude resolution of $150 \mathrm{~m}$ and a time resolution of approximately $3 \mathrm{~min}$ between each scan cycle of five beams. On each day the observation was carried out during 09:00-16:30 LT. The small data gaps in the time series of data were filled using linear interpolation in height and time based on linear averaging of data points on either side of the data gap. Since significant time averaging was involved in deriving the profiles of momentum flux to be presented, the interpolation was not considered to be significant. Though the observation was carried out within the altitude range of 3.6 to $30 \mathrm{~km}$, the analysis was limited to 3.75 to $20 \mathrm{~km}$ range, in order to have good SNR $[\geq-10 \mathrm{~dB}]$.

From the Doppler spectra in the bin range separated by $150 \mathrm{~m}$, the zonal $(u)$, meridional $(v)$, vertical $(w)$ components of wind profiles were obtained for each cycle of five beams, providing a time series of $u, v, w$ during each day of observation. The method of calculation of the three wind components is described in detail by Rao et al. (1995). The maximum value of zonal wind speed obtained was approximately $45 \mathrm{~m} / \mathrm{s}$, blowing in the easterly direction and occurring at about $16 \mathrm{~km}$. The maximum value of meridional velocity was $15 \mathrm{~m} / \mathrm{s}$. The maximum value of the vertical wind obtained was about $6 \mathrm{~m} / \mathrm{s}$.

\section{Observation of wind pattern and its variations}

\subsection{Mean wind pattern}

The typical mean zonal, meridional and vertical wind values at Gadanki $\left(13.47^{\circ} \mathrm{N}, 79.18^{\circ} \mathrm{E}\right)$ are given in Fig. 1. The
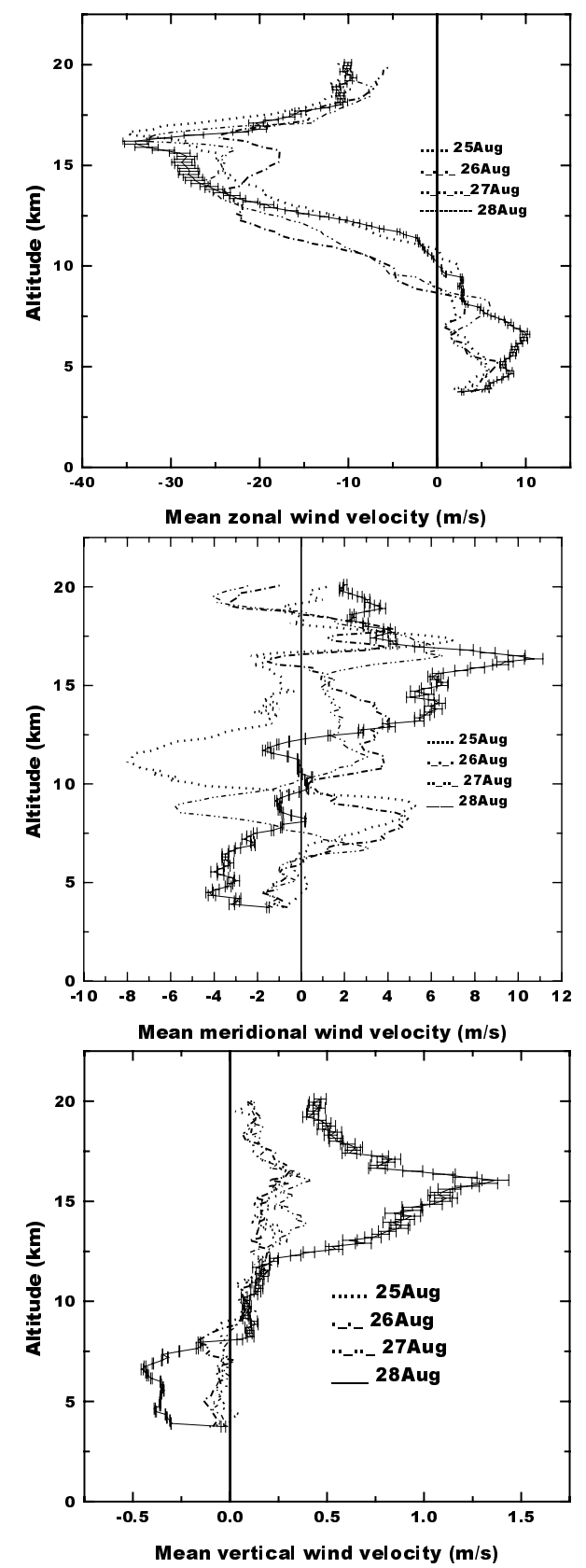

Fig. 1. Mean zonal (top), meridional (middle) and vertical (bottom) wind velocity during 25-28 August 1999.

mean zonal wind (Fig. 1 top) for all four days of observation remain westerly, up to $10 \mathrm{~km}$ altitude and above $10 \mathrm{~km}$, the zonal wind is easterly. In the case of the meridional wind (Fig. 1 middle), during the four days of observation, the wind fluctuates between the northern and southern directions at all altitudes, unlike the zonal wind which remains almost stable during the four days of observation. The mean vertical wind pattern is given in Fig. 1 (bottom). On all four days, the average vertical wind is downward, up to about $8 \mathrm{~km}$ and upward above this altitude. Also, the mean vertical wind is very high on 28 August compared to the other days. This 


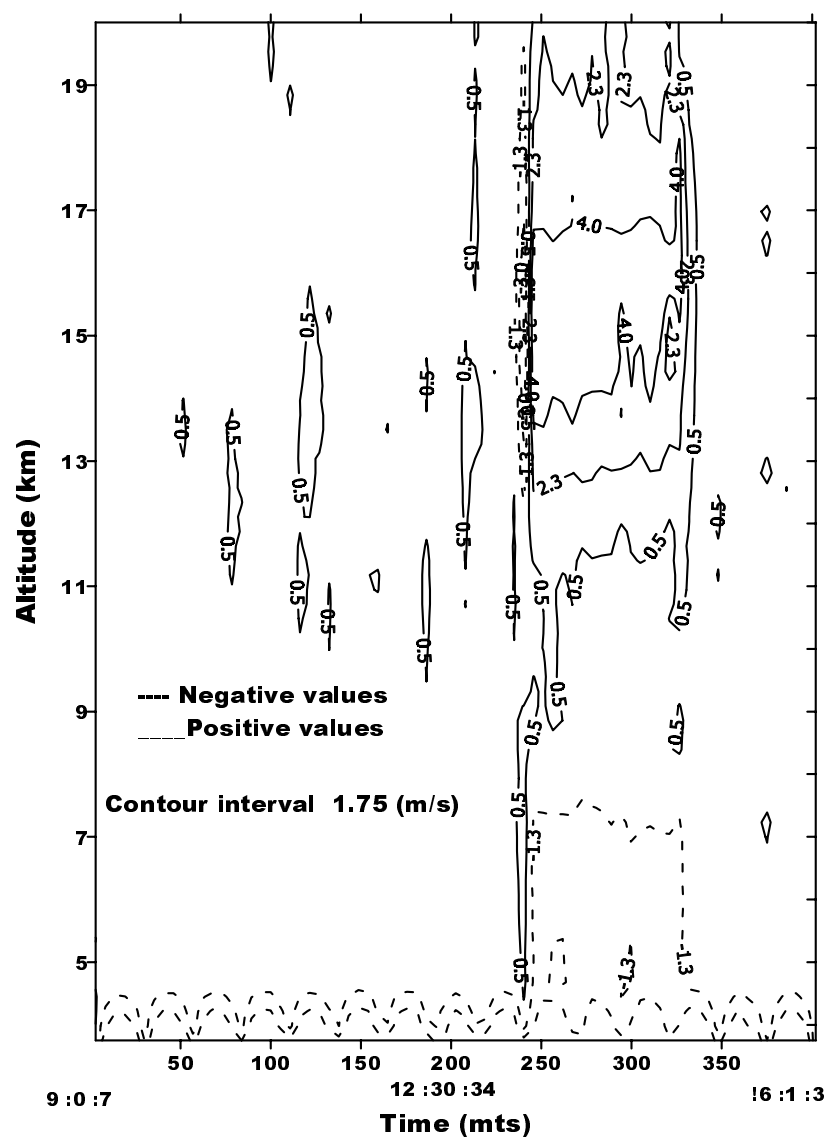

Fig. 2. Evolution of vertical wind with time and altitude on $28 \mathrm{Au}-$ gust 1999, 09:00 to 16:00 LT. Full lines indicate upward wind and dashed lines indicate downward wind. Contour interval is $1.75 \mathrm{~m} / \mathrm{s}$.

increase in mean vertical wind is due to a strong convection event that occurred on that day. The magnitude of the mean vertical wind velocity for 25 to 27 August 1999 is less than $0.3 \mathrm{~m} / \mathrm{s}$. During 28 August 1999 , the mean vertical velocity has a magnitude greater than $1 \mathrm{~m} / \mathrm{s}$, due to a strong convection that occurred during the afternoon (13:00 to 14:30 LT) of that day, as noted in Fig. 1 (bottom). Figure 2 depicts the contour graph of the temporal evolution of the vertical wind in the altitude range $3.75 \mathrm{~km}$ to $20 \mathrm{~km}$. During the first three days (25-27 August 1999), short duration enhancements in vertical wind lasting about $20-30 \mathrm{~min}$ are seen. But on 28 August 1999, as seen from Fig. 2, the vertical wind remained up to a magnitude above $2 \mathrm{~m} / \mathrm{s}$ for about $90 \mathrm{~min}$ in the downward direction in the altitude range 4 to $8 \mathrm{~km}$ and up to $6 \mathrm{~m} / \mathrm{s}$ in the upward direction in the altitude ranges $12-16 \mathrm{~km}$. It is interesting to note the presence of a short duration downdraft preceding the updraft in the 12 to $16 \mathrm{~km}$ altitude range and a short duration updraft preceding the downdraft in the 4 to $8 \mathrm{~km}$ altitude range.

\subsection{Wind shear and convection}

Figure 3 depicts the wind shear observed on 28 August in the height range 5 to $20 \mathrm{~km}$. The full line contours indicate

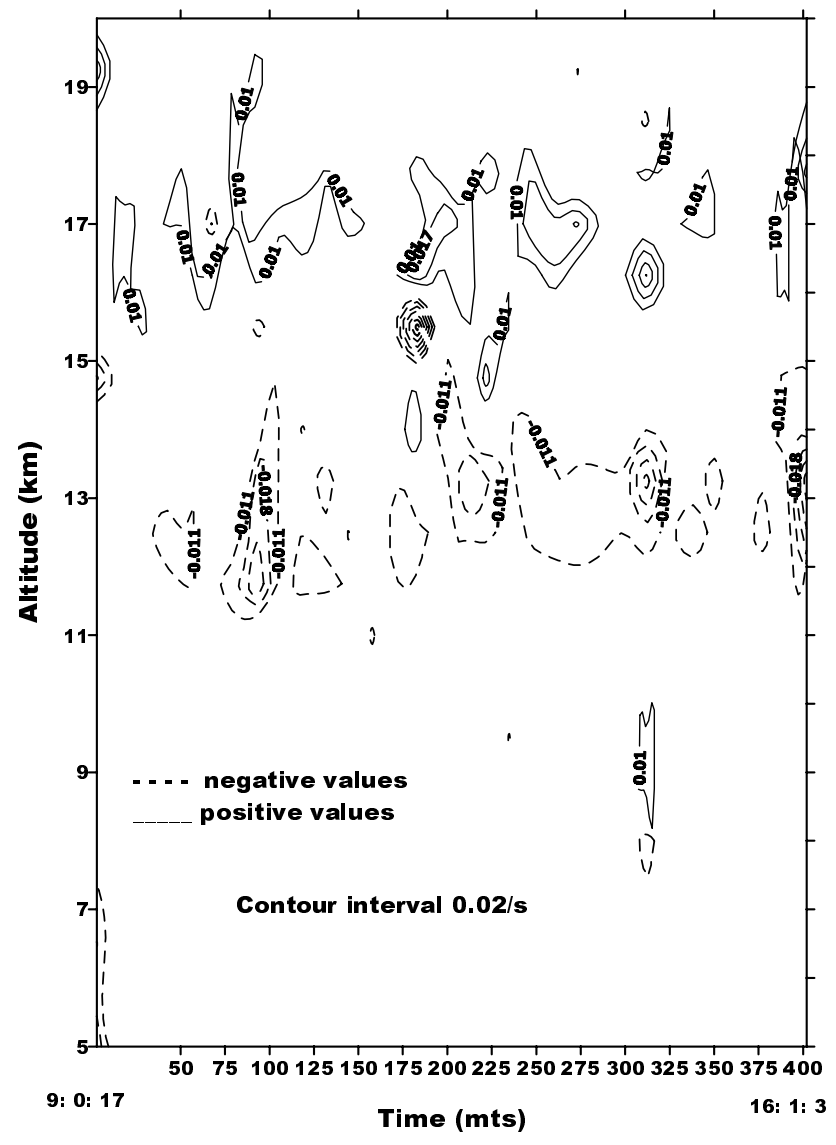

Fig. 3. Zonal wind shear on 28 August 1999, 09:00 to 16:00 LT. The full line indicates positive shear and dashed line indicates negative shear. Contour interval is $0.07 \mathrm{~s}^{-1}$.

positive values of shear, and the dashed line contours indicate negative values of shear. The maximum value of mean zonal wind shear obtained during the days of observation is about $\pm 0.03 \mathrm{~s}^{-1}$. The individual values of zonal wind shear actually rises up to a maximum of $\pm 0.3 \mathrm{~s}^{-1}$. The large wind shears can result in the excitation of gravity waves (Nakamura et al., 1993; Clark et al., 1986). As noticed from Fig. 1, the mean zonal shear, in general, is negative in the altitude range 7 to $16 \mathrm{~km}$, as the wind is increasing westward and then becomes positive at higher altitudes as the wind turns eastward. A typical contour profile of evolution of zonal shear and its altitude dependence is depicted in Figure 3. During this period, as seen from Fig. 3, the zonal shear is negative in the altitude range $12-13 \mathrm{~km}$ altitude (dashed lines) and positive around 16 to $17 \mathrm{~km}$ altitude range (full line). A strong short duration positive shear around $9 \mathrm{~km}$ and a negative shear around $8 \mathrm{~km}$ is also observed at the end of the convection event (14:30 LT). The wind components $u, v, w$ are subjected to Fourier analysis, in order to obtain the prominent periods of gravity waves, and we obtained prominent periods ranging from 10 to $100 \mathrm{~min}$.

The enhancement in the magnitude of vertical velocity seen in Fig. 2 can be associated with a feature such as frontal system clouds. Vertically propagating waves are launched 


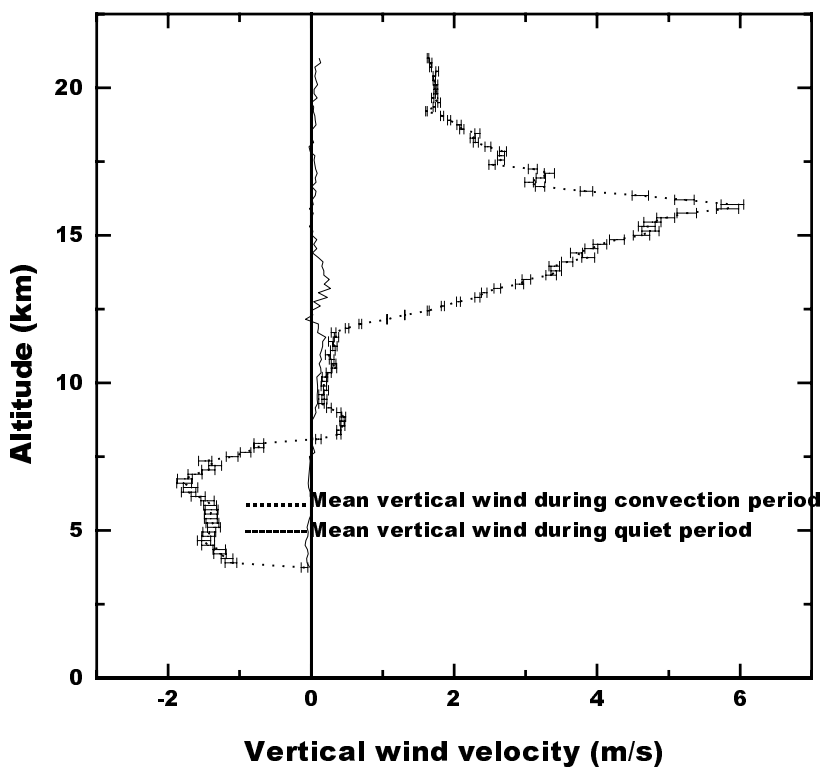

Fig. 4. Convection event on 28 August 1999: vertical profiles of mean value of vertical wind during both convection (dotted with error bars) and non-convection periods (full line).

when low stability leads to clouds and thunderstorms, when a source of dynamic instability, such as front or strong wind, is present (Rao et al., 1998a). This result is connected with the presence of gravity waves in the troposphere and lower stratosphere, as discussed in Sect. 3.4. It is found that large variances of vertical velocity are associated with low stability in the troposphere, most often indicated by clouds and convection and less frequently due to a dynamic feature, such as strong wind or front.

\subsection{Evolution of convection and radar reflectivity}

The intensity of the vertical wind gives an idea of the intensity of the convective event present in the troposphere. On 28 August 1999 (Fig. 2), a strong vertical updraft can be seen above $10 \mathrm{~km}$ and it rises to a height of about $16 \mathrm{~km}$ below the tropopause. Considering the covection event, an interesting feature is the downdraft below $7 \mathrm{~km}$ with a magnitude of about $1-4 \mathrm{~ms}^{-1}$.

Figure 4 depicts the mean value of the height profile of vertical velocity during the convection period (dotted line with error bars) and that during the non-convective period (full line) on 28 August 1999. During the convection period, the vertical mean velocity is in the downward direction in the altitude range 4 to $7 \mathrm{~km}$ and in the upward direction above $11 \mathrm{~km}$, with a peak updraft around $16 \mathrm{~km}$. From Fig. 4, it is also noticed that in the lower altitudes, the downdraft exhibits two peak values: one around $4 \mathrm{~km}$ and another around $7 \mathrm{~km}$, whereas the updraft in the higher altitude region exhibits a single peak value around $16 \mathrm{~km}$. During the non-convection period, the magnitude of average vertical velocity remained less than $0.3 \mathrm{~m} / \mathrm{s}$.

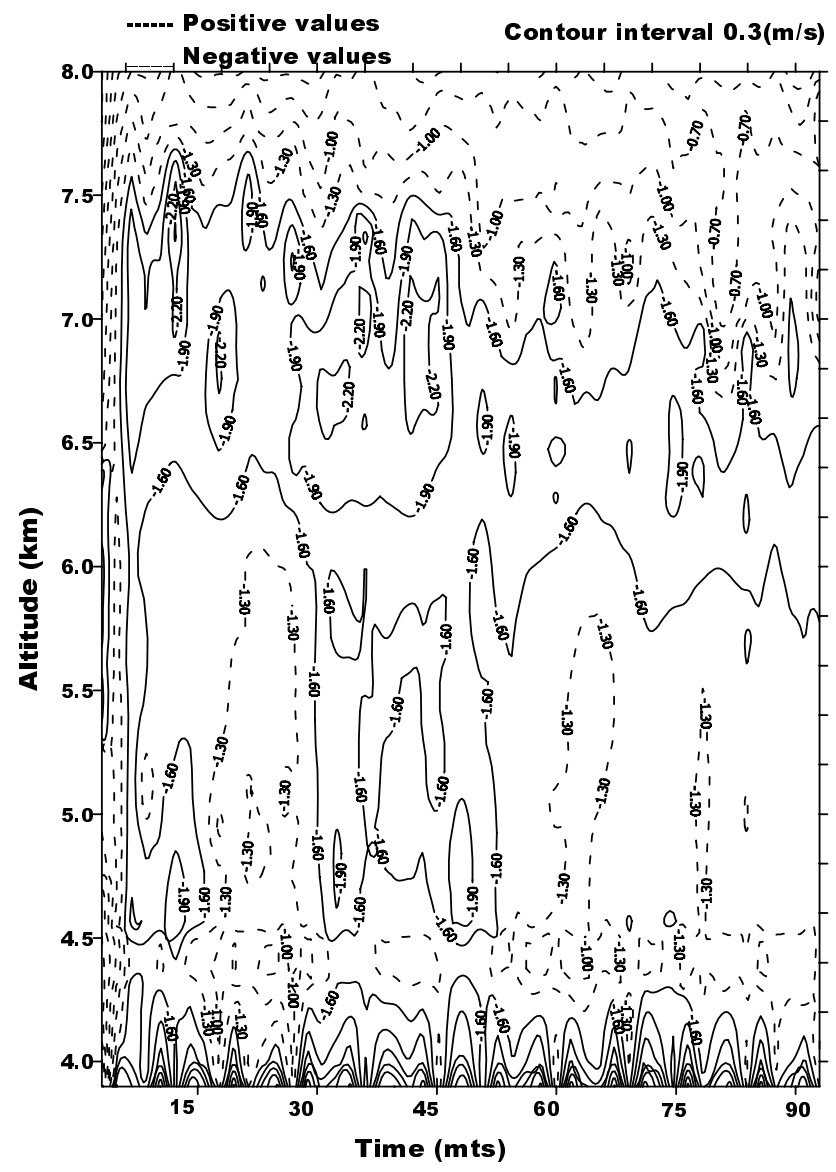

Fig. 5. Evolution of downdraft during the convection event on 28 August 1999: 13:00 to 14:30 LT. Full lines indicate downdraft and dashed lines indicate updraft and the contour interval is $0.3 \mathrm{~ms}^{-1}$.

To understand the nature of the medium during the convection event, the evolution of radar reflectivity was compared with that of convection during the convection event of 28 August 1999. Figure 5 depicts the evolution of convection in the lower altitudes during the convection period. The contour map of vertical wind exhibits a band of downdraft region around $7 \mathrm{~km}$. During the period of intense downdraft, downward velocity is seen to cover an entire range of altitude from $7 \mathrm{~km}$ downward for a short period of about $20 \mathrm{~min}$. Cooling, due to the melting of precipitation particles, along with evaporation, plays an important role in initiating and maintaining the downdraft beneath the anvil cloud base. The radar reflectivity is defined as the range squared corrected power of VHF radar echoes and can be used to monitor and study the temporal development of the inversion layer, frontal boundaries and convective turbulence (Rottger et al., 1986; Dhaka et al., 2001). The growth of reflectivity is well linked with turbulence. To study the radar reflectivity pattern during the convection event of 28 August 1999, the vertical beam data of MST radar have been used.

Figure 6 depicts the contour map of the radar reflectivity pattern during the 90-min convection period on 28 August 1999. Maximum reflectivity is seen as two bright bands: one 


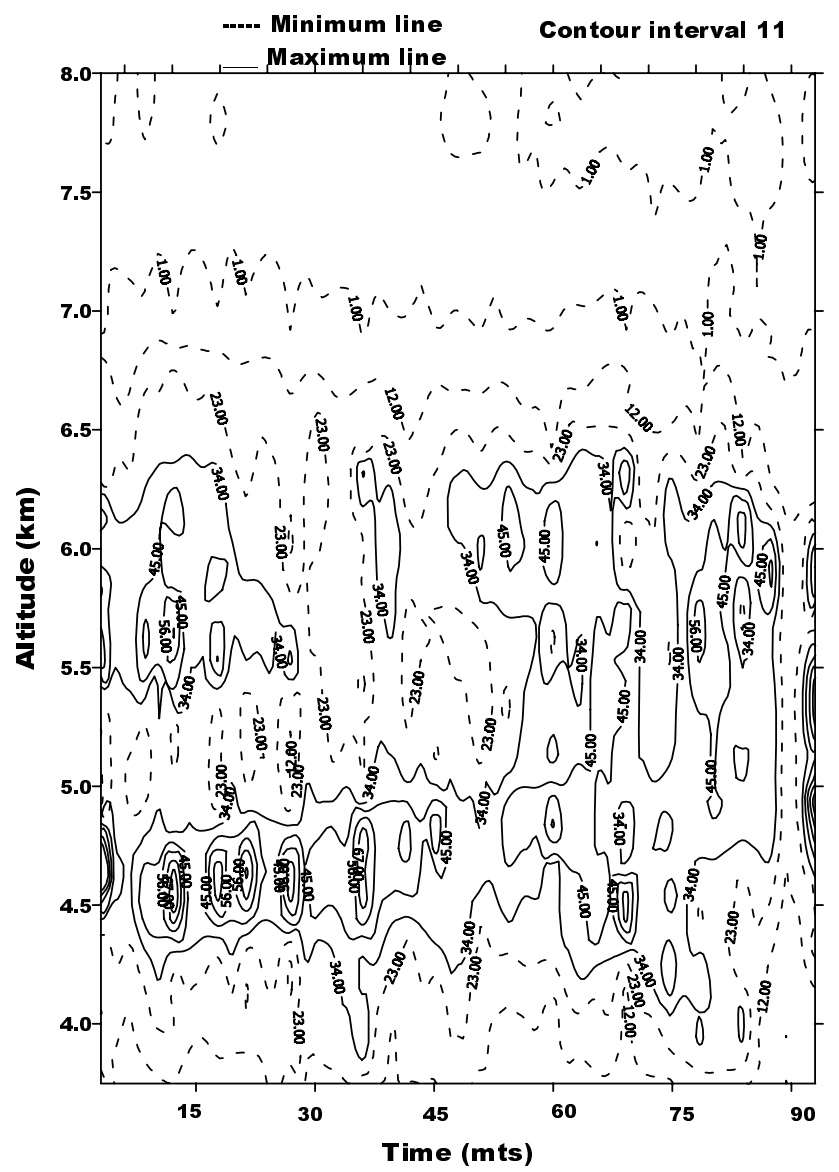

Fig. 6. Evolution of reflectivity (arbitrary unit) during convection event on 28 August 1999: during 13:00 to 14:30 LT.

around $6 \mathrm{~km}$ and another around $4.5 \mathrm{~km}$. The intensity (in arbitrary units) of the bright bands is comparable. The lower bright band is seen as a continuous patch and the upper one has a break in between. The bright band around $6 \mathrm{~km}$ is associated with precipitation, becomes distorted and breaks during the intense downdraft, where velocities are characteristically greater than terminal fall speeds of particles.

Figure 7 depicts the height profile of the mean radar reflectivity during the convection period (dashed lines) and during a non-convection period (full lines). The radar reflectivity is generally stronger below $7 \mathrm{~km}$ and then falls rapidly with a minor enhancement around the tropopause heights. In general, as seen from Fig. 7, the magnitude radar reflectivity is less during a convection period compared to that during a non-convective period, both at the lower altitudes and at the tropopause. On the lower altitudes, the reflectivity is maximum in the altitude range $4-7 \mathrm{~km}$ and split into two layers, one just below $5 \mathrm{~km}$, corresponding to a bright band of the radar and the second around $6 \mathrm{~km}$. The disappearing of the reflectivity at the tropopause during convection may be due to the masking by larger magnitude intensity at lower altitude or due to the weakening of the tropopause stability during the period of continuous updraft (Dhaka et al., 2001).

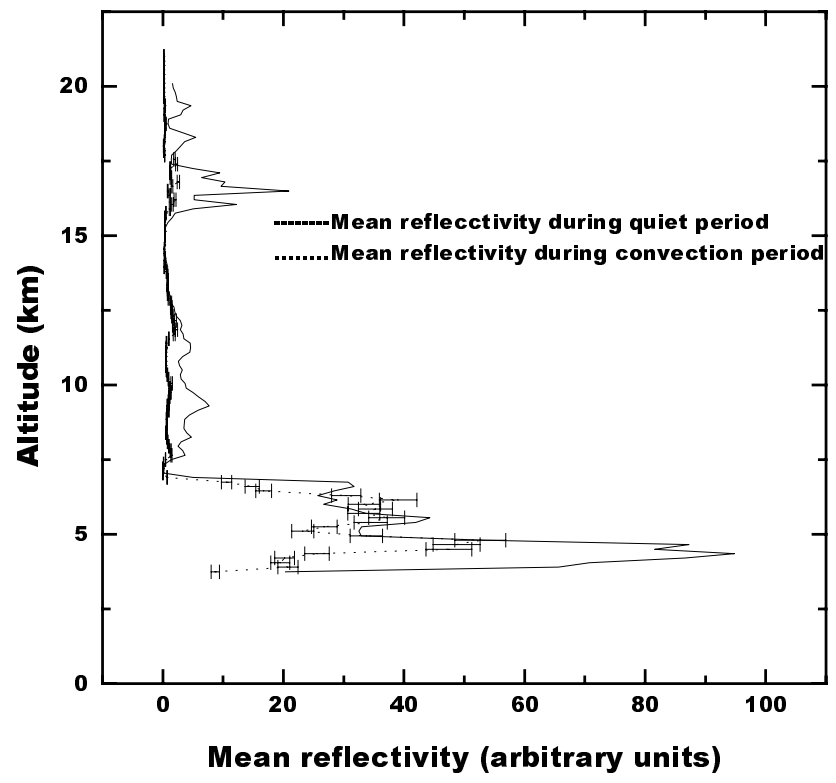

Fig. 7. Mean radar reflectivity profile during convection event (dotted curve with error bar) and that during the non-convection time (full line) on 28 August 1999.

\subsection{Generation of gravity waves}

The generation of gravity waves by convection can be due to a variety of processes: (i) the mechanical oscillator effect in which the oscillating updraft and downdraft air parcels impinge on the interface between the stable and unstable region, which, in turn, excite vertically propagating gravity waves (Fovell et al., 1992), (ii) obstacle effect in which gravity wave forcing occurs when a pressure field produced by rising convective element acts as an obstruction to the environmental horizontal flow (Pfister et al., 1993) and (iii) direct thermal forcing which offers the wave generation solely from the space time forcing of adiabatic heating fields (Alexander and Pfister, 1995). For the 28 August 1999 convection, the mean wind was about $35 \mathrm{~m} / \mathrm{s}$ and the vertical wind velocity was downward, up to $7 \mathrm{~km}$ altitude. Above this altitude, the updraft increases up to about $16 \mathrm{~km}$ and then decreases. From the reflectivity pattern, it is noticed that the medium is turbulent up to the mid-troposphere. The radar reflectivity does not show rapid growth. The medium in the upper troposphere is stable and seems to be continuously distributed from the lower side. This is in good agreement with the pre-condition set forth for the mechanical oscillator effect, which requires continuous impinging at, or above the mid-troposphere level by the updraft and downdraft of vertical wind. However, it is worth emphasizing here that these are tentative results in the sense that the direct observation of temperature and humidity are not available in the location which could be helpful in understanding the stability of the atmosphere. The deviations of the wind associated with convection from the background mean value indicate the presence of wave activity (Karoly et al., 1996). The location of a bright band, together with 
the melting and evaporation below the anvil cloud, suggest that cooling due to melting plays a role in the initiation and maintenance of the downdraft (Leary and Houzer, 1979).

\section{Estimation of momentum flux}

\subsection{Techniques}

In the symmetric-beam radar method of Vincent and Reid (1983), momentum flux is evaluated by comparing the Doppler shifts caused by gravity wave wind oscillations in back-scattered radar echoes from the atmosphere, using two or more beams offset from the vertical. This expresses the zonal component of vertical momentum flux $\overline{u^{\prime} w^{\prime}}$ in terms of the mean square radial velocities observed in a certain data interval as

$\overline{u^{\prime} w^{\prime}(z)}=\frac{\overline{V_{E}^{\prime 2}(z)}-\overline{V_{W}^{\prime 2}(z)}}{2 \sin (2 \theta)}$.

Here, $\theta$ corresponds to the zenith angle of the antenna beams and $V_{E}^{\prime}$ and $V_{W}^{\prime}$, are the line-of-sight perturbation velocities measured by the east and west beams as a function of altitude $z$. The overbar means a time average over the entire period of observation (about $7 \mathrm{~h}$ ). The radial velocity variances are calculated at each height $z$ and for each beam. These variances were used to estimate the momentum flux by using Eq. (1). Similarly, the meridional component of momentum flux $\overline{v^{\prime} w^{\prime}}$ was calculated by using the formula

$\overline{v^{\prime} w^{\prime}(z)}=\frac{\overline{V_{N}^{\prime 2}(z)}-\overline{V_{S}^{\prime 2}(z)}}{2 \sin (2 \theta)}$,

where $\overline{V_{N}^{\prime 2}}$ and $\overline{V_{S}^{\prime 2}}$ are the radial velocity variances measured by the north and south beams, respectively. Using the above two equations, zonal and meridional components of momentum flux values are obtained for the whole duration of observation, at each height and the vertical profiles of momentum fluxes are obtained for each of the four days. Momentum fluxes were also obtained as a function of frequency following Sato $(1989,1990)$. This method of calculation is an expansion of the symmetric beam method of Vincent and Reid (1983). This method makes use of two frequency spectra of radial velocities instead of mean squares. The two power spectra of radial velocities, $P_{V \pm \theta}(\omega)$, are expressed as (Sato, 1989)

$$
\begin{aligned}
& P_{V \pm \theta}(\omega)=U(\omega) U^{*}(\omega) \sin ^{2} \theta+W(\omega) W^{*}(\omega) \cos ^{2} \theta \\
& \quad \pm \operatorname{Re}\left[U(\omega) W^{*}(\omega)\right] \sin 2 \theta,
\end{aligned}
$$

where $\omega$ is the observed frequency, $U(\omega)$ and $W(\omega)$ are the Fourier components of horizontal and vertical velocities, respectively, and $U^{*}(\omega)$ and $W^{*}(\omega)$ show the complex conjugates. The term $\operatorname{Re}[U(\omega) W *(\omega)]$ in Eq. (3) shows the vertical momentum flux associated with gravity waves having a frequency $\omega$, which is calculated from Eq. (3) as

$\operatorname{Re}\left[U(\omega) W^{*}(\omega)\right]=\frac{P_{V_{+\theta}}(\omega)-P_{V_{-\theta}}(\omega)}{2 \sin 2 \theta}$.
The total vertical momentum flux is obtained from the spectra as

$\overline{u^{\prime} w^{\prime}}=\sum_{\omega} \operatorname{Re}\left[\left(U(\omega) W^{*}(\omega)\right]\right.$.

Similarly, the meridional component of momentum flux was also obtained from the power spectra of radial velocities of the north and south beams

$\overline{v^{\prime} w^{\prime}}=\sum_{\omega} \operatorname{Re}\left[\left(V(\omega) W^{*}(\omega)\right]\right.$.

The zonal and meridional momentum fluxes were computed by this method for each height range for the approximately 7-h duration and the height profile of momentum flux is obtained for each day. The momentum flux spectra obtained from Eq. (4) is also presented in contour maps of vertical flux variation as functions of frequency and altitude in Fig. 16. The right-hand side of Eq. (4) is used for calculating the momentum flux. Even though mathematically the two equations in the SB and PS methods are equal, there is a change in the concept of the medium. The SB method is used under an assumption of a homogeneous field of disturbance for symmetric beam pairs, to evaluate the radial velocity variances. But in the case of convection events, vertical velocity is large and it is difficult to exhibit the wave components by any filter method. Hence, momentum flux can be determined by replacing spatial average with time average. In the PS method spatial average is replaced with time average and was used by Sato (1990), for the study of momentum flux associated with larger vertical wind disturbance event. The PS method is applied is under an assumption that the phase passing occurs equally at the two symmetrical beam pairs instead of assuming homogeneous field of disturbances. During convection periods with strong vertical disturbances, the PS method yields better results than the SB method (Sato, 1990). The vertical wind disturbances have large temporal fluctuations with high frequencies and it is difficult to extract the wave components from the wind data using any filter for time or height, because the waves have similar time and vertical scales to background wind. So, the power spectral method can be used in a disturbed period. The sample spectrum of radial velocities of east, west, north and south beams on 25 and 28 August 1999 are depicted in Figs. 8 and 9.

The spectrum of radial velocities at $14.1 \mathrm{~km}$ altitude corresponding to the east-west pair of beams and the north-south pair of beams exhibits a weak asymmetry on 25 August 1999 in contrast to that on 28 August 1999, a day with strong convection. This spatial asymmetry will lead to the difference in the result of the evaluation of momentum flux using SB and PS methods, in addition to the asymmetry introduced by limiting the period range in our calculation. To study the temporal evolution of momentum flux, $\overline{u^{\prime} w^{\prime}(z, t)}$ and $\overline{v^{\prime} w^{\prime}(z, t)}$ for the zonal and meridional winds were evaluated for each altitude range. Here, the overbar denotes the average over a few cycles. 


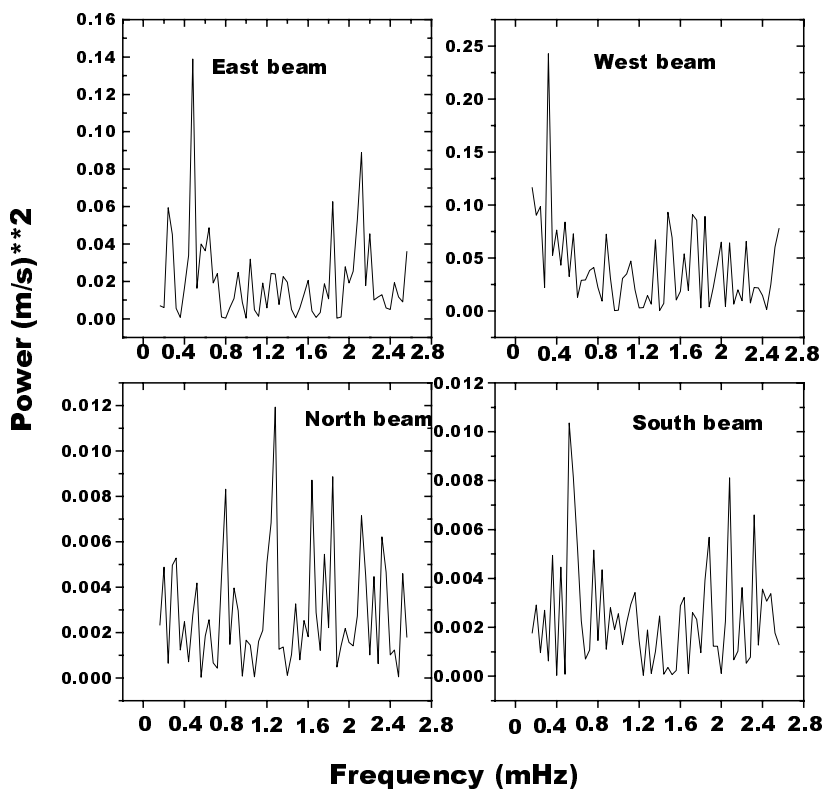

Fig. 8. The spectrum of radial velocities observed using east, west, north and south beams at $14.1 \mathrm{~km}$ altitude on 25 August 1999 .

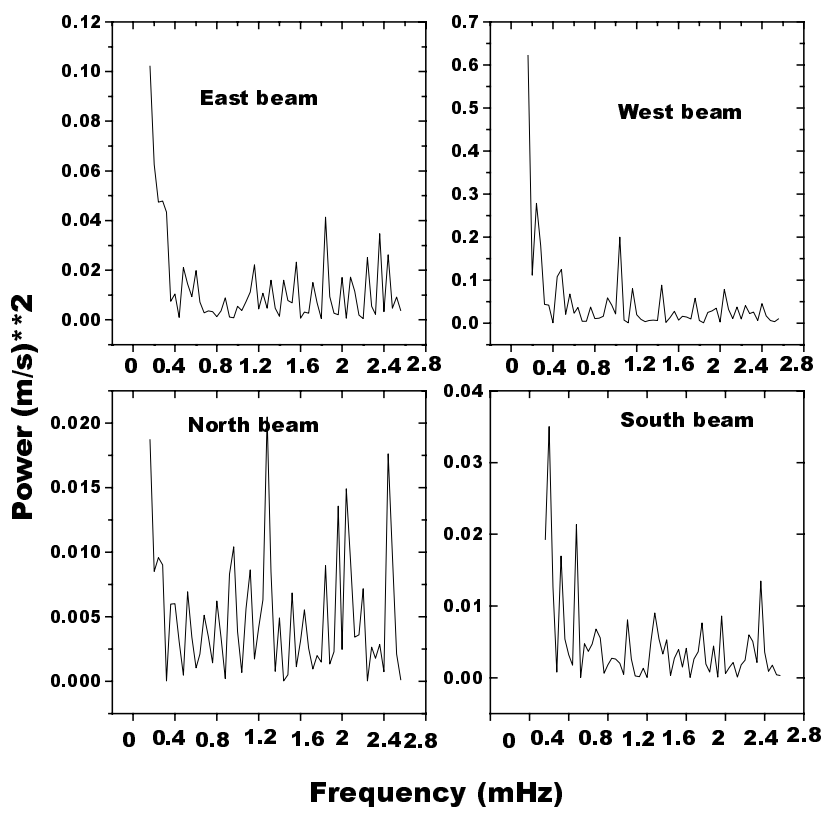

Fig. 9. The spectrum of radial velocities observed using east, west, north and south beams at $14.1 \mathrm{~km}$ altitude on 28 August 1999.

\subsection{Momentum flux profiles}

Upward flux of zonal and meridional momentum were computed for each day using the symmetric-beam (SB) radar method of Vincent and Reid (1983) given by Eqs. (1) and (2) and the power spectral method (PS) of Sato (1990), given by Eqs. (5) and (6). Figure 10 depicts the zonal momentum flux for 25, 26, 27 and 28 August 1999. The vertical profiles of the zonal momentum flux by both the methods are given in Fig. 10.

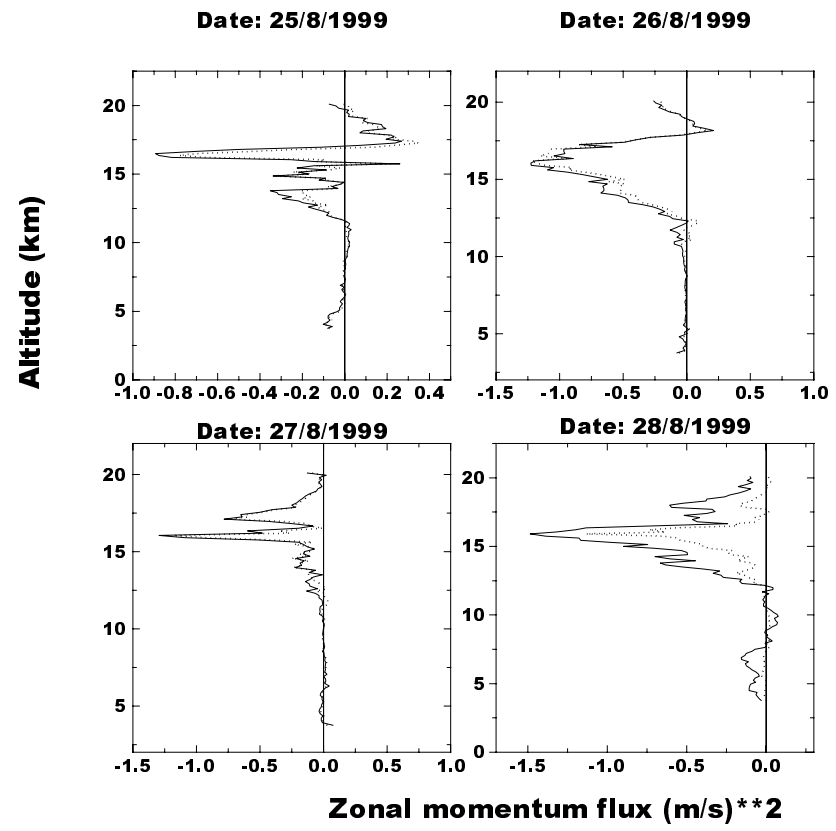

Fig. 10. Mean zonal momentum flux profiles for 25, 26, 27 and 28 August 1999 evaluated using the SB method (full lines) and the PS method (dashed lines).

The full line in Fig. 10 represents the calculations by the SB method and the dashed line represents the calculations by the PS method. From Fig. 10, it is clear that both the methods are giving nearly the same results for all days, except on 28 August 1999. Since atmospheric fluctuations are statistically homogeneous, averaging in time, as in the case of the SB method, and averaging frequency, as in the case of the PS method, give nearly the same result for the zonal momentum flux profiles for the days without strong convection. However, significant deviations in magnitude is seen between the two results during 28 August 1999, a day with strong convection. This deviation is due to the spatial asymmetry introduced by the convection. In all four days of observation, the profile of zonal momentum flux showed nearly the same pattern, with a peak value around the $16 \mathrm{~km}$ altitude and a magnitude range around -1.5 to $0.2 \mathrm{~m}^{2} \mathrm{~s}^{-2}$. Figure 11 depicts the vertical profile of meridional momentum flux during 25 , 26, 27 and 28 August 1999. The zonal momentum flux profiles have nearly the same pattern on all 4 days. Unlike the zonal momentum flux, the meridional momentum flux values vary considerably with respect to altitude and exhibit day-today variations. The zonal momentum fluxes are smaller in magnitude at lower heights, but they increase in negative sign at higher altitudes. On average, large zonal momentum fluxes are observed around height ranges of 13 to $16 \mathrm{~km}$ altitude near the easterly jet. This suggests the negative acceleration of the mean zonal wind above the height of the peak and a positive acceleration below it, which tends to strengthen the vertical shear of the mean wind. On the other hand, no clear pattern is seen in the case of meridional wind momentum flux at these height levels, and also, the flux values are compara- 


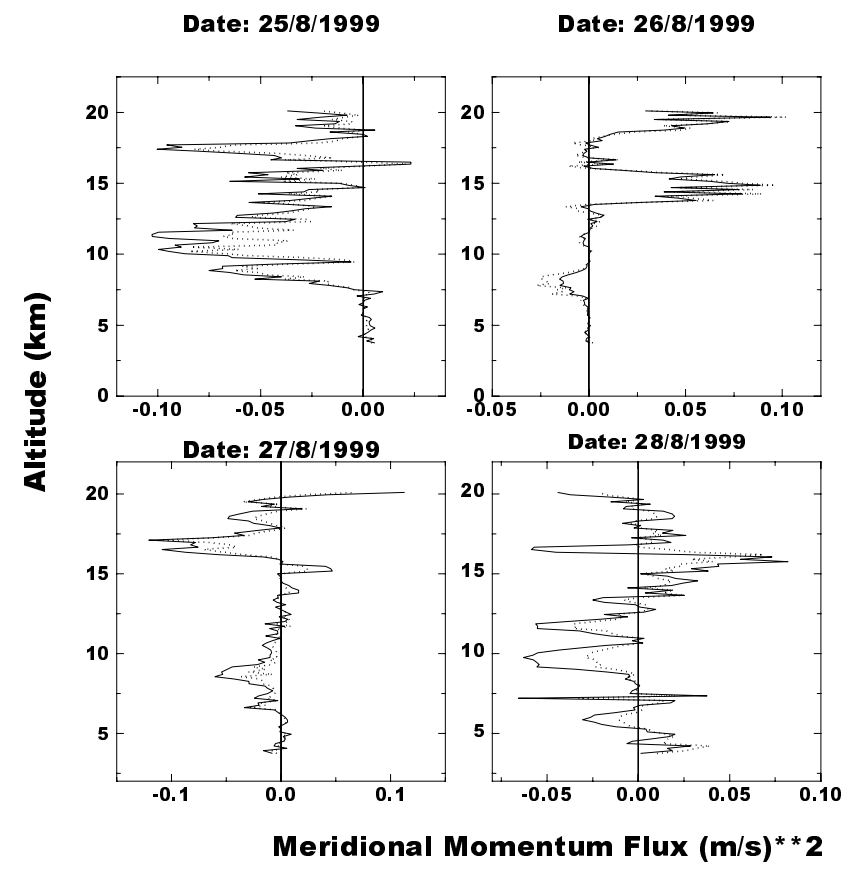

Fig. 11. Mean meridional momentum flux profiles for 25, 26, 27 and 28 August 1999 using the SB method (full lines) and the PS method (dashed lines).

tively one order less than the zonal component. From a comparison with Fig. 1, we can see that the pattern of zonal and meridional momentum flux are closely related to the background wind pattern. The zonal momentum flux tends to be large and negative where the mean zonal wind velocity is westward with a negative wave number vector (Sato, 1990). For the meridional wind such a correlation can also be seen. The magnitude of meridional momentum flux is nearly onetenth of the magnitude of the zonal momentum flux. This may be due to the lack of significant anisotropy of meridional wave activity. From Figs. 10 and 11, it is clear that momentum flux in the zonal component is biased towards the negative side and the fluxes corresponding to the meridional wind is distributed between both the positive and negative sides. This indicates that most of the gravity waves which contribute to momentum flux have wave number vectors directed westward during the period of observation. Considering the day-to-day variations of zonal momentum flux, we can see from Fig. 10 that there is only a slight change in daily average values. On average, the mean zonal momentum flux values change from $-1.5 \mathrm{~m}^{2} \mathrm{~s}^{-2}$ to $0.3 \mathrm{~m}^{2} \mathrm{~s}^{-2}$, with a negative maximum at around the $16 \mathrm{~km}$ altitude. The zonal momentum flux value is maximum on 28 August 1999 and minimum on 25 August 1999. The meridional momentum flux values on average fluctuate from -0.1 to $+0.1 \mathrm{~m}^{2} \mathrm{~s}^{-2}$ on the 4 days, at different altitudes. Compared to the zonal momentum flux, day-to-day variations in the meridional momentum flux are larger. The momentum flux associated with zonal wind exhibits a very large enhancement around the $16 \mathrm{~km}$ al-
Date: 28/8/1999 Time: 9: 0: 7 to 16: 1: 3

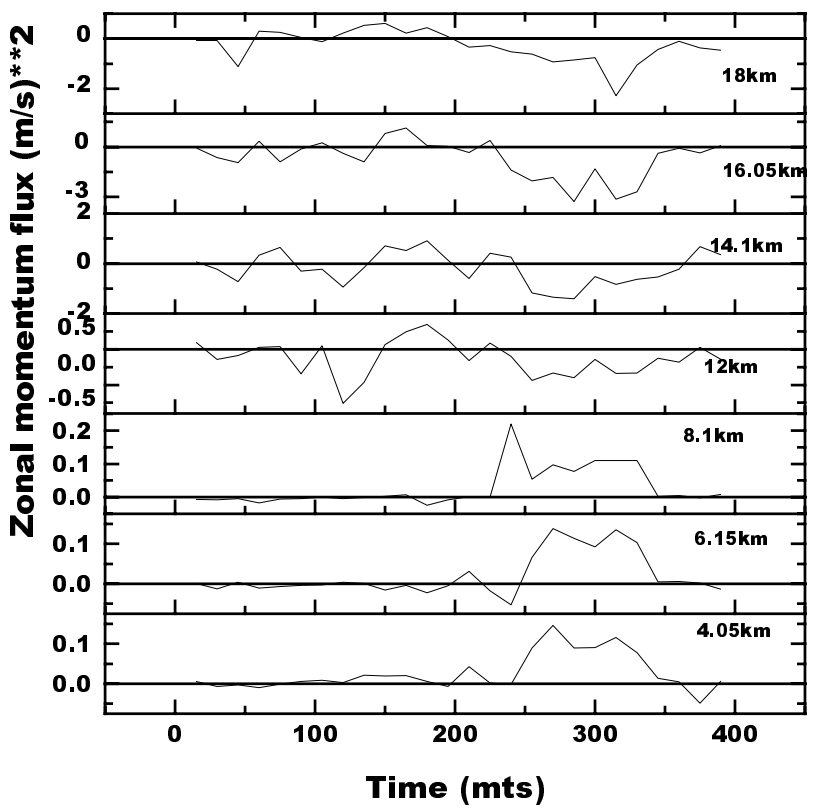

Fig. 12. Time evolution of zonal momentum flux on 28 August 1999 during 09:00 to 16:00 LT.

titude compared to that associated with meridional wind. On the day with strong shear, the zonal momentum flux exhibits a positive value in the 10 to $12 \mathrm{~km}$ altitude range and negative values in rest of the altitudes, whereas the mean meridional momentum flux on the same day exhibits both positive and negative values, with an increase in the negative direction around $11 \mathrm{~km}$ and increase in the positive direction around $16 \mathrm{~km}$. Similar variation can be noticed in the meridional wind depicted in Fig. 1 (middle). A qualitative idea about how much mean wind is changed due to the zonal momentum flux deposition can be obtained from Fig. 1 (top) and Fig. 3. Figure 3 reveals that the zonal shear grows in the negative direction around the $13 \mathrm{~km}$ altitude and increases in the positive direction around the $16 \mathrm{~km}$ altitude at the end of the convection event.

\subsection{Momentum flux and convection}

Figure 12 presents the time variation of the vertical flux of zonal momentum flux in the altitude ranges from 4 to $18 \mathrm{~km}$ on 28 August 1999. The zonal momentum flux is evaluated using the SB method and averaged over about $15 \mathrm{~min}$. Even though a high degree of temporal variability in zonal momentum flux is seen from Figure 12, a significant momentum flux determination can only be obtained by averaging it over reasonably longer periods (Kudeki and Franke, 1998). In this work, our aim is to study the response of downdraft and updraft on the short period changes in the momentum flux. During 13:00 LT to 14:30 LT, associated with the convection event, the vertical flux of zonal momentum exhibits an increase to positive values at lower altitudes, 4 to $8 \mathrm{~km}$, 


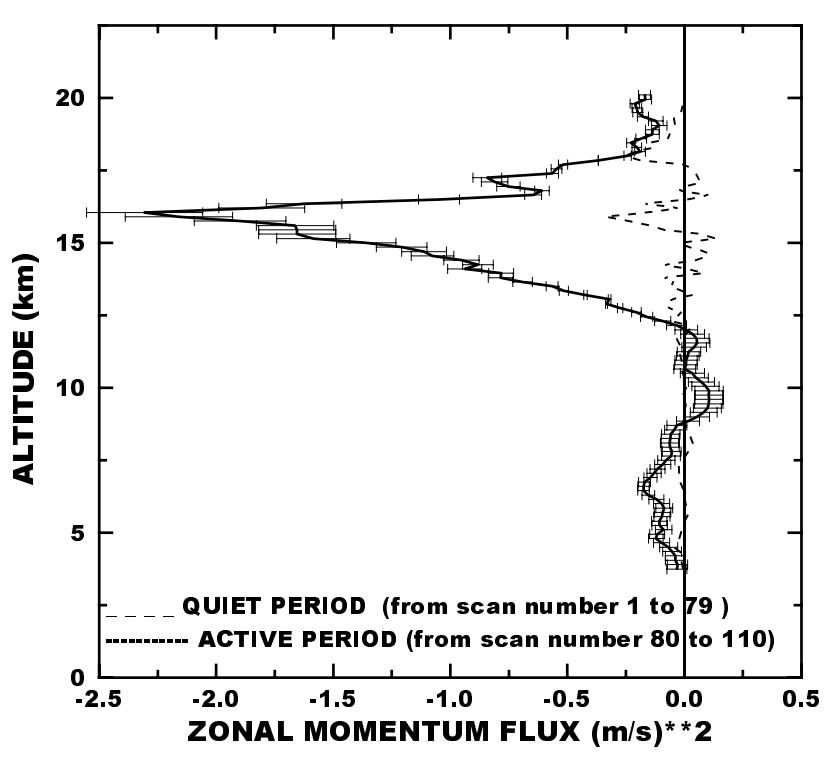

Fig. 13. The average zonal momentum flux during the convection event (full line with error bars) and during a period without convection (dotted line) on 28 August 1999.

and a decrease at the higher altitudes during the convection event. From Fig. 2 it is noticed that on 28 August 1999, during 13:00 to 14:30 LT, the vertical velocity had larger negative values in the 4 to $8 \mathrm{~km}$ altitude range and positive values at higher altitudes. This indicates that vertical wind velocity variation and vertical flux of zonal momentum are anticorrelated during a convection event on 28 August 1999. The average zonal momentum flux evaluated during the convection period and that during the quite period are depicted in Fig. 13. It is noticed from Fig. 13 that the vertical flux values at $16 \mathrm{~km}$ during a convection period is 10 times the flux during a non-convection period.

Figure 14 exhibits the time variation of meridional momentum flux evaluated using the SB method. Even though the meridional momentum flux shows fluctuations in lesser amplitude compared to that associated with zonal momentum, at the start of the convection event an abrupt change is seen in the meridional momentum flux. This change is towards the negative direction at the 4 to $8 \mathrm{~km}$ altitude range and in the positive direction at higher altitudes, as seen from Fig. 14, with its amplitude growing to a maximum value at the $18 \mathrm{~km}$ altitude. This abrupt change coincides with the short period updraft in the 4 to $8 \mathrm{~km}$ altitude and a downdraft in the 12 to $16 \mathrm{~km}$ altitude ranges depicted in Fig. 2. Similarly, a large fluctuation in the meridional flux is seen at the $12 \mathrm{~km}$ altitude at the end of convection.

The average meridional momentum flux evaluated during the convection period and non-convection period on $28 \mathrm{Au}-$ gust 1999 is depicted in Fig. 15. During the convection period, the magnitude of momentum flux corresponding to

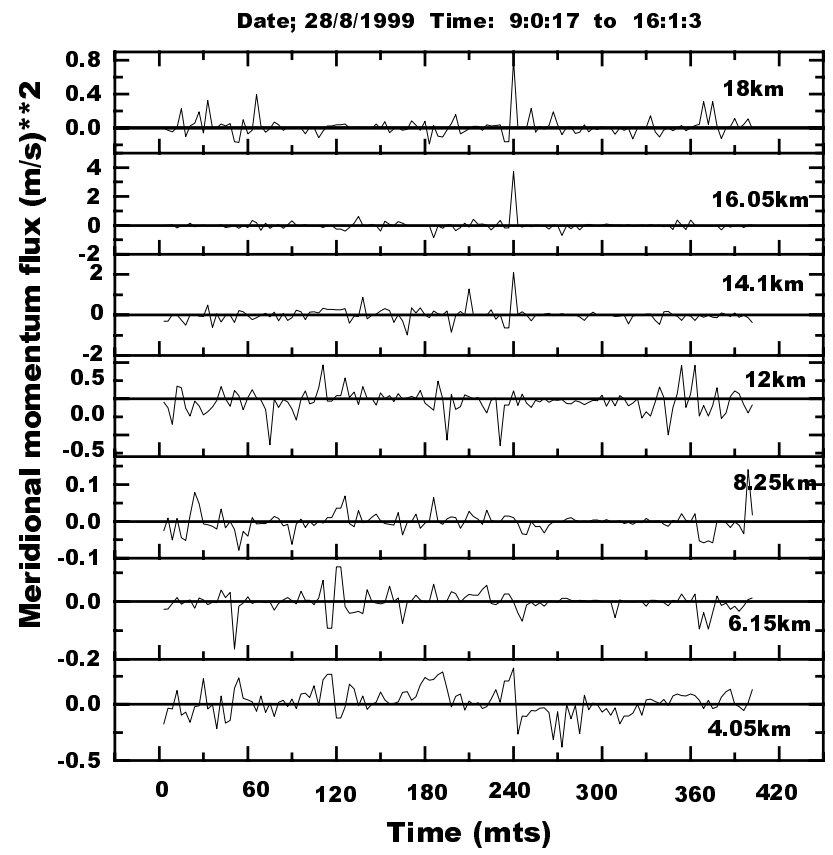

Fig. 14. Tme evolution of meridional momentum flux for 28 August 1999 during 09:00 to 16:01 LT.

meridional wind is larger at all altitudes. From Fig. 15, it is noted that the meridional momentum flux exhibits a strong enhancement at about the $10 \mathrm{~km}$ altitude, associated with convection. This altitude corresponds to the top of the downdraft region where the gravity waves are generated. Similar enhancement in meridional momentum flux is also noticed around the $15 \mathrm{~km}$ altitude.

\subsection{Frequency dependence of momentum flux}

The zonal momentum flux evaluated using the power spectral method is shown in Fig. 16 as contour plots. The contour maps depict the dependence of the zonal momentum flux as a function of gravity wave period and altitude. It is seen from the figures that zonal momentum flux is maximum at height ranges of $13 \mathrm{~km}$ to $16 \mathrm{~km}$ on all 4 days, as seen in the case of SB method (Fig. 10). The lower cutoff period is kept at $10 \mathrm{~min}$ due to the Brunt Vaisälä cutoff which is around $10 \mathrm{~min}$ in the troposphere. The higher cutoff is kept at $100 \mathrm{~min}$, since beyond this period the spectrum goes below the confidence level due to the limit in the data length. Within this limit of periods, maximum momentum transport occurs at wave periods between 12 to $96 \mathrm{~min}$. A small day to-day variation can also be observed in the case of these periods, suggesting that very different wave propagation effects at different times. The prominent periods associated with maximum zonal momentum flux are 12, 25, 35, 48, $60 \mathrm{~min}$. From the height average values, it is found that greater momentum is transported by long period or short frequency gravity waves. It is significant from Fig. 16 that the zonal momentum flux is giving maximum values and also 


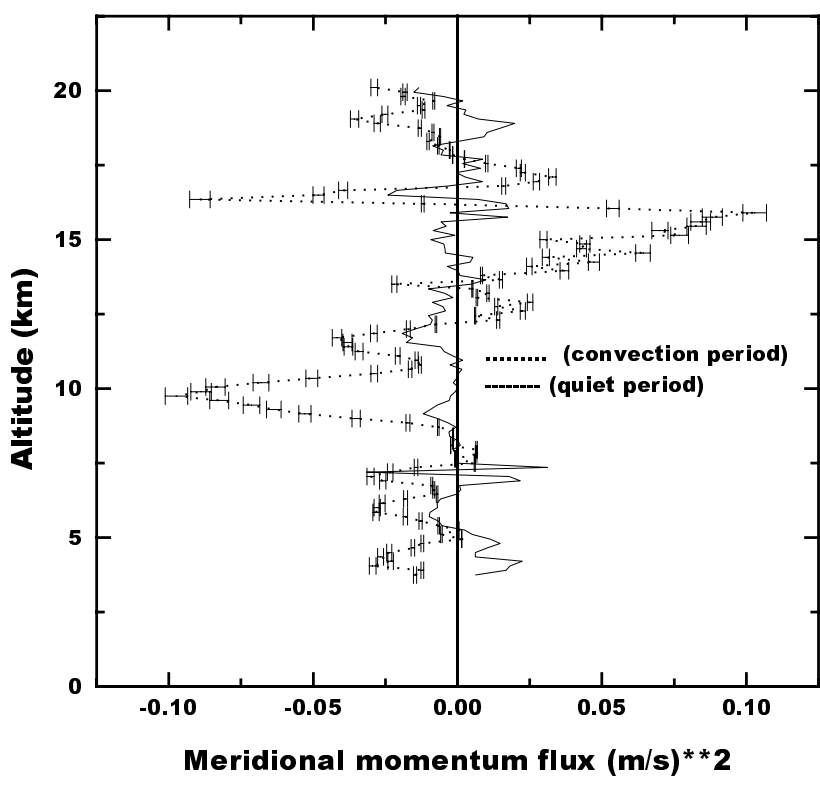

Fig. 15. The average meridional momentum flux during the convection event (dotted line with error bar) and during a period without convection (full line) on 28 August 1999.

that the higher momentum flux is observed at the longer period on 28 August 1999, compared to the other days.

\section{Results and discussions}

Convection and wind shear can produce gravity waves which transfer mean momentum flux between the layers of the atmosphere. In this work, the mean momentum flux is derived for four days using MST radar observation. The zonal and meridional momentum flux are evaluated using the symmetric beam (Vincent and Reid, 1983) and power spectral methods (Sato, 1989, 1990). During the days of observation, as seen from Fig. 1, the mean zonal wind has large westward velocity of about $35 \mathrm{~m} / \mathrm{s}$ around the $16 \mathrm{~km}$ altitude. Similarly, the mean meridional wind also depicts large variations. On 28 August 1999, the mean vertical wind showed large deviation from the values of the other days, in addition to the strong zonal shear. This situation provides an excellent opportunity to study the dependence of momentum flux values on the wind shear and the convection. The time evolution of the vertical wind and zonal wind shear during 28 August 1999 in the altitude range of 4 to $20 \mathrm{~km}$ are shown in Figs. 2 and 3. From Fig. 4 it is noted that the mean value of the vertical wind is much higher than that during the non-convection period. During the convection period (13:00 to 14:30 LT), the vertical wind exhibits a temporal evolution with a strong downdraft. The features of the evolution of this downdraft are compared with the radar reflectivity, which during the period of convection is seen as two bright bands of nearly the same intensity. The upper bright band exhibits a breaking during the strong downdraft. The gravity waves associated with the convection are generated at the stable region of the atmosphere top above the convection region around the $10 \mathrm{~km}$ altitude. A similar feature is seen above $15 \mathrm{~km}$ at the top of the updraft region. While a negative shear is seen at the top of the downdraft region around $12 \mathrm{~km}$, a region of positive shear is observed above $16 \mathrm{~km}$, at the top of the updraft region. Alexander and Pfister (1995) have shown that gravity waves propagate away from deep convection. The effect of the transfer of momentum from one region of the atmosphere to another can be seen from the changes in the mean flow acceleration (Chang et al., 1997). Fritts et al. (1990) calculated vertical fluxes of zonal momentum per unit mass as $-0.1 \mathrm{~m}^{2} \mathrm{~s}^{-2}$ to $0.1 \mathrm{~m}^{2} \mathrm{~s}^{-2}$ and found that near the tropopause jet, it is associated with a net acceleration of approximately $1-2 \mathrm{~ms}^{-1} \mathrm{~d}^{-1}$. The relation between the gravity wave activity and convection can be seen from the changes in the background wind associated with convection. The wind shear depicted in Fig. 3 exhibits peak negative values aound $13 \mathrm{~km}$ and peak positive value around $16 \mathrm{~km}$ at the end of the convection, at the stable region at the downdraft and updraft regions. The vertical momentum flux obtained at the upper troposphere shows that the large negative value in the vertical zonal flux and positive meridional flux are associated with the presence of strong zonal shear and updraft that existed below those altitudes and the associated spatial and temporal asymmetry between the east and west beams. Similarly, the strong negative meridional momentum flux seen around the $10 \mathrm{~km}$ altitude is associated with the downdraft region that existed below $10 \mathrm{~km}$.

Figures 10 and 11 depict a comparison of the profiles of the vertical flux associated with the zonal and meridional momentum for the four days of observation. It is noticed that the magnitude and pattern of the momentum flux value, in general, is comparable to the results of early radar and non-radar studies of vertical flux (Fukao et al., 1988; McAfee et al., 1989; Sato, 1989; Worthington et al., 1996; Alexander and Pfister, 1995; Chang et al., 1997). In general, the momentum flux pattern and its general characteristics observed in the present work are similar to that of the observations mentioned above. The estimation of momentum flux magnitude at the Indian MST radar site by Rao et al. $(1997,1998)$ and Sasi et al. (1998) are also in agreement with the present results. The momentum flux values and its pattern observed in the present work compared to the results of others mentioned above are due to the differences in the wind conditions. The large vertical momentum flux values observed around the $16 \mathrm{~km}$ altitude on all days of observation are associated with the presence of large zonal shear at that altitude during the period of observation. This result is in agreement with the observations of large zonal momentum flux around jet streams reported by Murayama et al. (1994) and Fritts et al. (1990). The direction of the zonal momentum flux obtained in the present work are also in agreement with that obtained by Sato (1989), Fritts et al. (1990) and Prichard and Thomas (1993). Such a correlation of zonal momentum flux with the background wind pattern is also observed by Fritts and Vincent (1987) and Rao et al. (1998a, b). The day-to-day variations of momentum flux observed in our study are also 

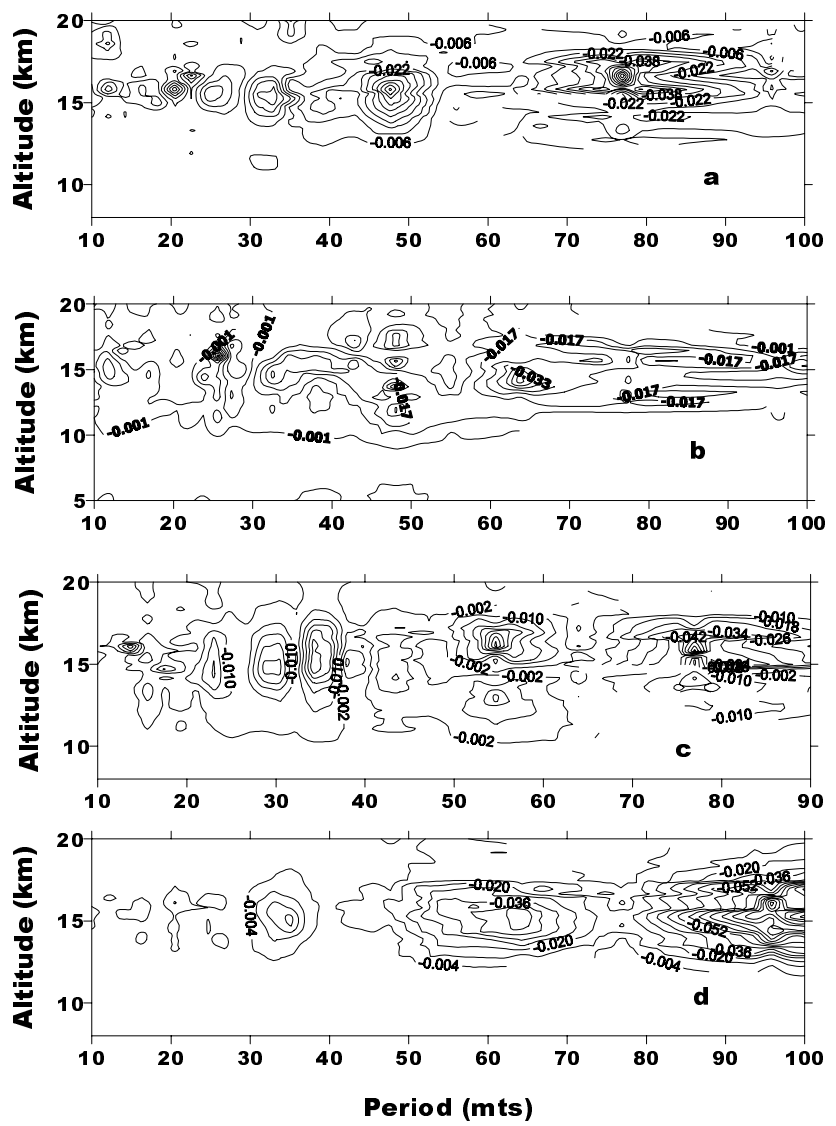

Fig. 16. The variation in the strength of zonal momentum flux with wave period and altitude for (a) 25, (b) 26, (c) 27 and (d) 28 August 1999. Contour interval is $0.008(\mathrm{~m} / \mathrm{s})^{2}$.

similar to those of Fritts et al. (1990), except for the larger values of momentum flux observed on 28 August 1999. The evaluation of the profile of the momentum flux associated with zonal and meridional wind using the SB method and the PS method exhibits nearly the same pattern, except for the day with strong convection. The SB method assumes a homogeneous field disturbance for symmetric beam pairs and in the PS method the spatial average is replaced by the time average. Since both the SB and PS methods provide the same profiles of momentum flux for 25, 26 and 27 August 1999, it is clear that the limitation in the spectral period in the present analysis has not affected the difference in momentum flux evaluation by the two methods. The spectra of radial velocities in the $14.1 \mathrm{~km}$ altitude depicted in Figs. 8 and 9 provides information about this difference. Although for 25 August 1999 (Fig. 8), the mean magnitude of the spectral power of radial velocities corresponding to the symmetric beam pairs is nearly same, during a day with strong convection a marked difference is seen. So, during strong convection, the spatial and temporal symmetry are distorted by the convection, giving a difference between the results obtained using the SB and PS methods. To summarise, the vertical flux associated with zonal and meridional momentum calculated by the symmetric beam and power spectral methods is giving nearly the same results during quite periods. However, during active periods, these two methods give different results. This difference is due to the spatial and temporal asymmetry between the pair of beams introduced by convection and shear.

On 28 August 1999, in addition to this zonal shear, a strong convection occurred around 13:30-14:30 LT. The temporal evolution of the momentum flux evaluated, associated with the zonal and meridional wind on 28 August, is depicted in Figs. 12 and 14. Figure 12 explains the time evolution of zonal momentum flux during 28 August 1999, associated with the convection event at different altitudes. Geophysical noise in the radar wind data introduces uncertainty in the momentum flux estimation (Kudeki and Franke, 1998). Averaging of the momentum fluxes over a long enough interval is necessary in order to calculate a realistic estimate of tropospheric momentum fluxes (Chang et al., 1997). Even though significant momentum flux determination can only be obtained by averaging over reasonably long periods (Kudeki and Franke, 1998), in the present work we have attempted to study the variations in momentum flux values associated with sharp changes in the wind field by realizing the uncertainties associated with it. At lower altitudes, the increase in momentum flux is associated with a downdraft in vertical wind during 13:00 to 14:30 LT. Similarly, at higher altitudes, negative momentum flux is associated with an increase in the vertical wind. This result indicates that the zonal momentum flux is inversely correlated with the vertical wind during convection events. Figure 13 exhibits the enhancement in the momentum flux associated with zonal wind during the convection period, compared to that during the non-convection period. Figure 14 exhibits the temporal evolution of the meridional momentum flux during the convection event. It is noticed that associated with the initial sharp change in the vertical wind the meridional momentum flux also exhibits a sharp pulse-like feature. This change in the negative direction in the lower altitudes is associated with sharp decrease in the vertical wind and in the positive direction in the upper troposphere it is associated with the sharp increase in the vertical wind. So, the change in meridional momentum flux is correlated with the change in the vertical wind.

From Fig. 12, it is noticed that the zonal momentum flux also shows wide variations during periods without convection at higher altitude range. This variation can be associated with the presence of zonal shear existing at those altitudes. In Fig. 13 the mean vertical flux profile associated with zonal momentum is shown for the periods with convection and during those periods without convection. It is noticed that during periods with convection the zonal momentum flux is enhanced many fold compared to other periods even though the zonal shear is present during both periods. The anti-correlation of momentum flux with vertical wind during the convection event found in our study is also in agreement with the results of Prichard and Thomas (1994). The association of higher values of momentum fluxes with strong vertical wind conditions obtained by Sato (1990) is also similar to our results during a convection event on 28 August. On average, the vertical flux associated with zonal 
wind and meridional wind during strong convection is larger compared to other periods, due to the spatial and temporal asymmetry introduced between the pair of beams by the convection.

The study of the variation of zonal momentum flux with a period of oscillation presented in Fig. 16 reveals that during quiet days the momentum flux is evenly distributed over all periods considered here. But during a day with strong convection, the zonal momentum flux magnitude is associated with longer periods. Since the frequency response of the zonal momentum flux is evaluated from the temporal asymmetry between the east and west beams, the vertical flux associated with zonal wind is proportional to the asymmetry between the spectrum of east and west radial velocities. It is noticed that the asymmetry in the spectrum of east and west radial velocities is maximum in the lower frequency region. So, during the day with strong convection, the zonal momentum flux is prominent around the short frequency region. The analysis of the dependence of wave periods on vertical momentum flux transport indicates that the zonal momentum flux is maximum at those wave periods for which the magnitude of temporal asymmetry between the pair of beams is maximum. So, the transport momentum and energy to higher altitudes depends on the wave period, which again is decided by the temporal evolution of convection and shear.

Acknowledgement. The authors thank National MST radar Facility, Gadanki, India and S.V. University, Tirupati for their help during the observation and data processing. One of the authors (SS) thank University Grants Commission for the award of a fellowship (FIP).

Topical Editor D. Murtagh thanks two referees for their help in evaluating this paper.

\section{References}

Alexander, M. J. and Pfister, L. P.: Gravity wave momentum flux in the lower stratosphere over convection Geophys. Res. Lett., 22, 2029-2032, 1995.

Bretherton, F. P.: Momentum transport by gravity waves Quart. J. Roy. Meteor. Soc., 95, 213-243, 1969.

Chang, J. L., Avery, S. K., Riddle, A. C., Palo, S. E., and Gage, K. S.: First results of tropospheric gravity wave momentum flux measurements over Christmas island, Radio Sci., 32, 727-748, 1997.

Clark, T. E., Hauf, T., and Kuettner, J. P.: Convectively forced internal gravity waves: Results from two dimensional numerical experiments, Quart. J. Roy. Meteor. Soc., 112, 899-925, 1986.

Dhaka, S. K., Devarajan, P. K., Shibagaki, Y., Choudhary, R. K., and Fukao, S.: Indian MST radar observations of gravity wave activities associated with tropical convection, J. Atmos. Solar Terr. Phys., 63, 1631-1642, 2001.

Fovell, R., Durran, D., and Holton, J. R.: Numerical simulation of convectively generated gravity waves, J. Atmos. Sci., 49, $11427-$ $11442,1992$.

Fritts, D. C. and Vincent, R. A.: Mesospheric momentum flux studies at Adelaide, Australia: Observation of a gravity wave tidal interaction model, J. Atmos. Sci., 44, 605-619, 1987.

Fritts, D. C., Tsuda, T., Vanzandt, T. E., Smith, S. A., Sato, T., Fukao, S., and Kato, S.: Studies of velocity fluctuations in the lower atmosphere using the M. U radar. Part II Momentum fluxes and energy densities, J. Atmos. Sci. 47, 51-66, 1990.

Fritts, D. C. and Vanzandt, T. E.: Spectral estimation of gravity wave energy and momentum fluxes. Part I Energy dissipation, acceleration and constraints, J. Atmos. Sci., 50, 3685-3694, 1993.

Fukao, S., Sato, T., Kato, S., Inaba, M., and Kimura, I.: VHF Doppler radar determination of momentum flux in the upper troposphere and lower stratosphere: Comparison between three and four beam methods, J. Atmos. Oceanic. Technol., 5, 57-69, 1988.

Gossard, E. E.: Vertical flux of energy in to the lower atmosphere from internal gravity waves generated in the troposphere, J. Geophys. Res., 67, 745-757, 1962.

Hines, C. O.: Dynamical heating of the upper atmosphere: J. Geophys. Res., 70, 177-183, 1965.

Hines, C. O.: Momentum deposition by atmospheric waves and its effects in thermospheric circulation, Space Res., 12, 1157-1161, 1972.

Houghton, J. T.: The stratosphere and mesosphere, Quart. J. Roy. Meteor. Soc., 104, 1-29, 1978.

Karoly, D. J., Roff, G. L., and Reeder, M. J.: Gravity wave activity associated with tropical convection detected in TOGA COARE sounding data, Geophys. Res. Lett., 23, 261-264, 1996.

Kudeki, E. and Franke, S. J.: Statistics of momentum flux estimation, J. Atmos. Solar Terr. Phys., 60, 1549-1553, 1998.

Leary, C. A. and Houze, Jr., R. A.: Melting and evaporation of hydrometeors in precipitation from the anvil clouds of deep tropical convection, J. Atmos. Sci., 36, 669-679, 1979.

Lindzen, R. S.: Lower atmospheric energy sources for the upper atmosphere: Meteor. Monogr., 9, 37-46, 1968.

Lindzen, R. S.: Turbulence and stress owing to gravity wave and tidal breakdown, J. Geophy. Res., 86, 9707-9714, 1981.

McAfee, J. R., Balsley, B. B., and Gage, K. S.: Momentum flux measurement over mountains: Problems associated with the symmetrical two beam radar technique, J. Atmos. Oceanic. Technol., 6, 500-508, 1989.

Murayama, Y., Tsuda, T., and Fukao, S.: Seasonal variation of gravity wave activity in the lower atmosphere observed with MU radar, J. Geophys. Res., 99, 23 057-23 069, 1994.

Nakamura, T., Tsuda, T., Yamamoto, M., Fukao, S., and Kato, S.: Characteristics of gravity waves in the mesosphere observed with the MU radar, J. Geophys. Res., 98, 8899-8910, 1993.

Pfister, L., Scott, S., and Loewenstein, M.: Mesoscale disturbances in the tropical strotosphere excited with convection: observations and effects on the stratospheric momentum budget, J. Atmos. Sci., 50, 1058-1075, 1993.

Prichard, I. T. and Thomas, L.: Radar observations of gravity wave momentum fluxes in the troposphere and lower stratosphere, Ann. Geophysicae, 11, 1075-1083, 1993.

Prichard, I. T. and Thomas, L.: Radar observations of mountain lee waves near the west cost of Wales, STEP Hand Book, Proceedings of the sixth workshop on technical and scientific aspects of MST radar edited by Belva Edwards, 223-227, 1994.

Rao, P. B., Jain, A. R., Kishore, P., Balamuraleedhar, P., Damle, S. H., and Viswanadhan, G.: Indian MST radar: System description and sample vector wind measurements in ST mode, Radio Sci., 30, 1125-1138, 1995.

Rao, D. N., Kishore, P., Narayana Rao, T., Vijayabhaskara Rao, S., Krishna Reddy, K., Yarraiah, M., and Hareesh, M.: Studies on refractivity structre constant, eddy dissipation rate and momentum flux at a tropical latitude, Radio Sci., 32, 1375-1389, 1997.

Rao, D. N., Narayana Rao, T., Kishore, P., and Kamala, S.: Seasonal 
variations of momentum flux in the troposphere at a tropical latitude, STEP Hand Book, Proceedings of the eighth workshop on technical and scientific aspects of MST radar, (Ed) Belva Edwards, 188-191, 1998a.

Rao, D. N., Kishore, P., and Vijayabhaskara Rao, S.: Gravity wave activity observed in the troposphere and lower stratosphere using Indian MST radar, STEP Hand Book, Proceedings of the eighth workshop on technical and scientific aspects of MST radar, (Ed) Belva Edwards, 115-118, 1998b.

Rao, D. N., Thulasiraman, S., Vijaya Bhaskara Rao, S., Narayana Rao, T., Kishore, P., Venkat Retnam, M., and Krishna Reddy, K.: VHF radar observations of tropical easterly jet stream over Gadanki, Adv. Space Res., 26, 943-946, 2000.

Rottger, J., Fu, L. J., Kuo, F. S., Liu, C. H., and Chao, J. K.: On the use of colour reflectivity plots to monitor the structure of the troposphere and stratosphere, Hand Book of MAP, (Eds) Bowhill, S. A. and Belva Edwards, 20, 489-490, 1986.

Sasi, M. N., Lekshmi Vijayan, Deepa, V., and Krishna Murthy, B. V.: Possible gravity wave generation and propagation in the tropical easterly jet region, STEP Hand Book, Proceedings of the eighth workshop on technical and scientific aspects of MST radar (Ed) Belva Edwards, 119-122, 1998.

Sato, K.: Momentum fluxes observed by the MU radar, under a strong vertical wind condition in the troposphere and lower stratosphere, Hand Book of MAP, (Ed) Belva Edwards, 28, 334339, 1989.

Sato, K.: Vertical wind disturbances in troposphere and lower stratosphere observed by the MU radar, J. Atmos. Sci., 47, 28032817, 1990.

Sato, K., Hashiguchi, H., and Fukao, S.: Gravity waves and turbulence associated with cumulus convection observed with the UHF/VHF clear-air Doppler radars, J. Geophys. Res., 100, 7111-7119, 1995.

Thomas, L., Prichard, I. T., and Astin, I.: Radar observations of inertia gravity waces in the troposphere and lower stratosphere, Ann. Geophysicae, 10, 690-697, 1992.

Tsuda, T., Murayama, Y., Yamamoto, M., Kato, S., and Fukao, S.: Seasonal variations of momentum flux in the mesosphere observed with the MU radar, Geophys. Res. Lett., 17, 725-728, 1990.

Vincent, R. A. and Reid, I. M.: HF Doppler measurements of mesospheric momentum fluxes, J. Atmos. Sci., 40, 1321-1333, 1983.

Vincent, R. A. and Fritts, D. C.: A climatology of gravity wave motions in the mesosphere region at Adelaide, Australia: J. Atmos. Sci., 44, 748-760, 1987.

Worthington, R. M. and Thomas, L.: The measurement of gravity wave momentum flux in the lower atmosphere using VHF radar, Radio Sci., 31, 1501-1517, 1996. 